\title{
Family and Peer Relationships in Children with Paranoid Delusions
}

\author{
Bettie Arthur Ph.D. University of Michigan Medical Center, Ann Arbor, \\ Michigan
}

Susanne Schumann, Ph.D. Eugene, Oregon

Psychoanaly tic theory links the origins of psychosis to a disruption of the individual's relationship with the object world. In order to regain the lost contact, the patient inaugurates restitutive procedures that involve a regressive reorganization of the ego the nature of which helps to determine the type of psychosis [1]. With minor modifications this generic formulation has been applied to psychotic conditions in both adults and children. The use of a generic theory to account for psychoses in both adults and children implies a relationship between the pathologies seen in children and adults. One need not maintain that the pathologies are identical, only that they are related with the deviant personality of the child possibly representing an anlage of the adult form of the psychopathology. It is, after all, logical to assume that psychopathology in adulthood emerges from a matrix of deviant personality development in childhood. There are several longitudinal as well as retrospective studies that appear to demonstrate the validity of this assumption, especially with regard to the psychoses $[2,3,4]$. Clinical experience with some childhood schizophrenics provides an opportunity to observe, in embryonic form, psychopathology that may reach full fruition only in the adult.

In some children the degree and direction of deviant development with its consequent disordered functioning is so severe that the child's psychopathology does, indeed, closely resemble adult mental disease. Such, we believe, is the case with the rare children who develop paranoid schizophrenia. Any clinician who has worked with emotionally disturbed children has at some time encountered patients whose overt behavior is characterized by intense anxiety, suspiciousness, underlying hostility, secretiveness, omnipotence, and a heavy reliance on the defense mechanism of projection. Only a very few of these children continue this line of development to the point where they actually crystallize a clinically discernible paranoid condition replete with persecutory and/or grandiose delusions. 
Recognition of paranoid conditions in childhood was long in coming. There are the classic papers by Klein [5] and Heimann [6:pp.122-68] on the development of persecutory anxiety (see also Josephs [7]), but the list of publications mentioning paranoid conditions or delusions in children is very small $[8,9,10,11,12,13,14]$. Most of these authors describe manifestations of paranoidlike symptomatology and particularly delusions in children as transient phenomena that are unlike the adult counterpart because of their general lack of structure and systematization. Many authors feel that the line between fantasy and reality is not drawn sharply enough in childhood and that the development and maintenance of a true delusional system requires greater cognitive development than the child has attained. The few authors who do describe phenomena akin to adult delusions in children do not always consider them indicative of a psychotic process and do not refer to them as paranoid in nature (cf. Kessler [15]).

We have had the opportunity to study several psychotic children whose symptomatology was highly similar to that of paranoid schizophrenia in adults and whose delusions were not as transient as suggested in the literature. The work of Lidz, Fleck, and Cornelison [16], Bateson [17:pp.116-22], Jackson and Weakland [18], and Wynne, Ryckoff, Day, and Hirsch [19] on the families of schizophrenics and the clinical studies on the development of adult paranoid conditions have shown that the families of schizophrenics employ unusual modes of relating to their environment. To our knowledge, this is the first attempt to study a restricted group of psychotic children with the aim of highlighting the connection between family relationships and the development of paranoid conditions in childhood and possibly in later life. In this paper we will describe the interpersonal relationships of paranoid schizophrenic children and attempt to understand how their family environment related to their paranoid adjustment and the fantastic elaboration of primitive fears and wishes.

\section{Subjects}

Since we wanted to study only children in whom a truly paranoid resolution had occurred, we sought basic criteria that would enable us to obtain as homogeneous a group as possible. To this end we strictly limited our selection to children manifesting clinically identifiable delusions of a paranoid type. Furthermore, the delusion had to remain stable over time (six months or more), and the child patient had to believe completely in its veracity during the time he held it; that is, we deliberately excluded all cases in which the delusions were transient manifestations of pathology, those who alternately proclaimed and disclaimed the reality of their fantastic world, as well as those patients who 
withdrew into highly complex fantasy worlds populated by one or more imaginary companions while knowing these were not real.

The cases that make up our sample were collected through our own clinical contacts with them and from the patient population evaluated and/or treated by other members of the staff at the Children's Psychiatric Hospital. The materials used for the initial selection and later description of our cases included reports from schools, physicians, community agencies and psychiatric referral sources, our own psychiatric and social casework intake interviews, psychological testing, and therapy notes on the patients and their parents, as well as detailed day-to-day nursing notes on the three patients who were hospitalized. The amount of information available on these patients varied because our clinical contacts with them ranged from evaluation data only to extensive inpatient treatment notes. (Three of the children included in this study were reported in an earlier paper by Harrison, Hess, and Zrull [14].)

After eliminating all doubtful cases from an original group of 31 children with highly elaborate fantasy productions, we found that the 13 patients who clearly fulfilled the stated criteria were preadolescent boys in the age range 8-11 to 13-9. The mean chronological age was 12 years $(s=18$ months). The IQs ranged from 80 to 121 with a mean of 101 (s - 10.5). In most cases the psychologist stated that the obtained IQ was an underestimate of a higher basic intellectual potential. The boys were not able to perform at a level commensurate with their potential because anxiety and disturbances of such vital ego functions as perception, thought processes, and reality testing were severe enough to seriously impair their overall functioning. The youngest patient in our group $(\mathrm{CA}=8-11)$ was also the brightest $(\mathrm{IQ}=121)$, which suggests, as others have observed, that it may be necessary for a certain level of cognitive development to have occurred before a child can develop, elaborate, and maintain a delusional belief. The psychiatric diagnoses of all the boys in our final sample fit into three classifications: borderline psychosis with paranoid features, childhood schizophrenia with paranoid trends, and paranoid schizophrenia.

\section{The Delusions}

The specific content of the delusions varied, but all showed both grandiose and persecutory features. We found no hypochondriacal delusions nor any true delusions of jealousy among the children in our final sample. While most of the delusions were not as systematized as found in adult patients, they were nevertheless fairly elaborate. In some instances the delusions became increasingly elaborate and structured over time: in others they were abandoned as the patient responded to treatment. 
Following are some illustrations of delusions in which grandiose elements were given the major emphasis:

Patient $\mathrm{H}$ : He was a former Egyptian king. A mummy would soon return from its tomb, murder him, and take him back to Egypt so as to restore him to the throne.

Patient K: He was the God Mercury, king of the Red Planet, a planet populated by mice. He later became Pixie, king of Pixie Land, another planet inhabited by mice, many of whom had names and elaborate characterizations. He had built a rocket with which he took trips to Pixie Land where, upon arriving, he would change into a mouse. He alone had control over travel to this planet. He was also the possessor of "top secret" information which he could not divulge to anyone. He was forced to take these extended trips to Pixie Land because people bothered him in his secret work. Later still, he was Mickey Mantle and played on the "Cooperstown team," a baseball team composed of fruits, for example, "bananas, peaches, lemons."

The delusions in which the major theme was persecutory are typified by the following examples:

Patient S: Mars men were out to get him. They wanted to make him jump out of a window into a long tube and then would shoot at him. At the bottom of the tube there would be several men "in corporal's uniform" waiting to beat him. They would make a slave out of him.

Patient B: Others were looking at him, watching him, manipulating him like a marionette on a string, and trying to run his life. All members of the hospital staff belonged to the Communist party, and they were out to get him, but he would outwit them all. He also claimed to own a construction company, a distillery, and a car manufacturing plant. To succeed in running them he had to outwit the hospital staff.

Patient H: Someone or something was following him. He was convinced it would turn out to be girls who wanted to chase him and carry him off to an unknown fate.

\section{Early Developmental History}

Except for two boys (one foster and one adopted child), all of the subjects had grown up with their natural parents, and the boys were living with their mothers. At the time of referral, all the boys were either the only or the oldest son living in the home. Siblings, if present, were reported as having no difficulties. The occupations of the fathers ranged from unskilled work to professional positions. All the mothers were housewives at the time of the evaluation. 
All the boys had several more or less severe clinical signs suggestive of early developmental disturbances, with most showing fixations at the oral or early anal phase of psychosexual development. The signs related to oral fixations included obesity, anorexia, peculiar food preferences, stealing of food, thumb sucking, and nail biting. Every boy manifested one or more of these. All the boys also had a history of problems around bladder and/or bowel training, and all had been enuretic and/or encopretic at some point in their lives, except one boy who suffered from a hand-washing compulsion. Sleep disturbances were also extremely common and included nightmares, night terrors, and insomnia.

With regard to temperament and mood, there were again gross deviations from normal patterning. The majority of boys were described as noticeably unpredictable and unstable, vacillating from affective blandness and quiet, detached, withdrawn behavior to inexplicable periods of elation, agitation, and/or aggressiveness. Two of the boys had made what appeared to be suicidal attempts: one slashed his wrist with a piece of glass, and the other jumped from a third-floor window at school.

\section{Development of Fantasy}

All the boys were reported to prefer spending their time pursuing some special circumscribed interest, for example, history, astronomy, space travel, electricity, rocketry, and designing war machinery of an idiosyncratic and unrealistic kind. Some of the boys read voraciously while others sat long hours making drawings or building models. All of these activities were related to the delusional systems. Due to the vagueness of the parents' reports, it was difficult to ascertain exactly when the preoccupation with these special interests started. But it is certain that all of the boys had had an unusual gift for "storytelling" and a history of fantasy preoccupation before they actually settled on a special interest area and long before they actually developed delusions. Their early fantasies were highly magical and included strong oral-sadistic and omnipotent strivings of a kind not too uncommon in bright preschool children. The only really unusual aspect of these early fantasy preoccupations seemed to lie in the great amount of time spent pursuing and elaborating them. Except for the youngest and brightest boy in our sample whose preoccupation with planets began at the age of three and who was actually living in a delusional world at the age of five, all of the other boys seemed to have developed their delusions at a later age, sometime during the early latency phase.

Like the earlier fantasies, the special, circumscribed interests often expressed oral-aggressive themes of war, punishment, torture, and death. The preoccupation with acquiring specialized knowledge was necessary to the later evolution 
of the fantasy and delusion. In several cases it was possible to trace the origin of the fantasy underlying the delusion to a traumatic episode or experience in the early life of the child (cf. Freud [25:pp.358-71] and Eissler [26]). For example, during early childhood the boy with the delusion about the mummy had his feet bound in the ancient Chinese manner by his father who thought the child's feet "too big."

\section{Relations to Adults}

Some of the boys habitually related to adults by asking incessant questions about their special interest area. For example, one boy always initiated contacts with men by inquiring how many persons they had killed in the war. In unfamiliar surroundings, the boys became hyperanxious and sometimes related to adults in a strikingly grandiose fashion. At these times they acted on their strong feelings of infantile omnipotence, attempted to order the adults around, and even threatened them in a grotesquely inappropriate fashion. Compared to their severe and continuous difficulties in relating to peers, however, it should be emphasized that ordinarily these youngsters had much less trouble and generally felt much less anxious in their social contacts with adults. In fact, most had an astonishing facility for engaging in rather appropriate though pseudo-adult and affectless conversations and interactions with adults. This capacity to simulate normality with adults was so well developed in the three boys who became inpatients that our highly trained and experienced psychiatric nursing staff occasionally seriously doubted the diagnoses of these youngsters. To some extent this same capacity was also noted during psychiatric interviews. It broke down completely in most peer relationships and in their highly disturbed response to the pressures of psychological testing. With regard to this observation we are reminded of Kovar's [21] description of the paranoid's ability to camouflage his feelings of estrangement by "as if" performances of socially outgoing, even gregarious, behavior.

\section{Peer Relationships}

All of the boys had severe difficulties in getting along with other children and were avoided, scapegoated, ridiculed, or bullied by peers because their "odd" and unpredictable moods and behaviors. By the time we saw these children most of them were "loners." They had had a long history of withdrawal into fantasy and later into their delusional world, a retreat sanctioned by their parents. There was, of course, much adaptiveness in their peers' rejection since all of the boys 
had something quite outlandish about them that peers could easily sense, if not observe directly. The odd behavior, the unusual preoccupations of these children, their never-ceasing interest in esoteric subjects made peers regard them as peculiar, and this in itself hampered their efforts to make contact with others outside the home. While our patients seemed vaguely aware of the basis for the rejection by peers and more or less directly admitted to feeling different from their age mates, none of them truly appreciated how unusual their behavior actually was. The resulting pain and frustration as well as bewilderment about peer rejection led eventually to an almost total withdrawal from peers in favor of relating to a few adults and to an even more intensive involvement with fantasy.

A further barrier to successful peer relationships and to the development of the social skills necessary to maintain them was created by the immature and almost unmodified infantile omnipotence displayed by these boys. There seemed to be no limit to their attempts at manipulating and dominating peers, and there was no recognition on the part of any of the boys or their parents that such behavior was doomed to failure. In fact, the parents would often reinforce the acting out of the boys' feelings of grandiosity by catering to and indulging them unrealistically in areas of behavior that reinforced the parental tie while protecting them from the potentially corrective experience of peer rejection. In some cases parents literally encouraged the boys to sever contact with peers altogether.

When they did interact with other youngsters at all, these boys preferred younger children as playmates, apparently because the latter were less threatening and more easily manipulated. A few were able to establish fleeting relationships with peers around a mutual interest in some exotic subject matter. However, these relationships were short-lived, being terminated as soon as the other child tired of the activity and turned to something else that our patients could not do because of their persistent and pervasive investment in the circumscribed area of interest. Then, too, the patients' know-it-all attitude and their efforts to indoctrinate peers by lecturing them in a superior way wore thin all too soon and contributed to the quick termination of the relationship. Subsequent to these failures in maintaining peer relationships the boys began to blame their peers for all troubles, expressed hostile feelings toward them, and finally withdrew even further into a world of their own making.

\section{School Adjustment}

Despite the parental (particularly maternal) reinforcement of intellectual pursuits, we found the boys to be poor competitors in school. Although some had done better in school earlier in their lives, most of them had severe learning 
problems when referred for evaluation. Despite frequently superior intellectual potential, albeit their esoteric interests in science and other complex matters, their voracious reading, and their often annoying habit of questioning adults endlessly in their special field of interest, the boys could not achieve well in school. Two had been able to read at the age of three, but even they could or would use their very advanced skills only in relation to their special interest area. Developing ego skills were subverted in their adaptive function as knowledge and academic skill were channeled primarily into the service of a narrow pathological development that eventually culminated in the delusional system. From cumulative school reports on these youngsters, it was apparent that adjustment to reality in terms of peer relationships, capacity for independence, and academic achievement had never been normal and became increasingly more disturbed over time. Kindergarten and first-grade reports mentioned immaturity, excessive dependence on the mother and/or teacher, quarrelsome behavior with peers, fears of normal aggression, little tolerance for frustration, and a highly variable attention span and activity level. At the time of referral several of the boys had been excluded from school altogether or were attending special classes for emotionally disturbed children. The most common complaints were the already mentioned severe mood swings, peculiar behaviors, learning difficulties, withdrawal into fantasy, and an inability to get along with peers. In several cases the schools had earlier advised the parents of the need for psychiatric help for their child but had had great difficulty because of the parents' hostile resistance to the idea.

\section{The Parents}

The following description of the parents will focus on examining possible links between their background, personality, and behavior on the one hand and the boys' pathology on the other

\section{The Mothers}

While only two of the mothers were clearly psychotic (both being paranoid schizophrenic), it was immediately apparent that all were deviant enough in their adjustment patterns to be considered clinically ill. We found a high incidence of paranoid tendencies coupled with marked masochistic, depressive, obsessivecompulsive, and/or hysterical character traits. Many seemed to have severe problems centering around their role as women. They voiced a variety of somatic complaints, and three had undergone surgery for unspecified "female troubles." The majority had been married for many years and were already over 30 when 
our patients were born. While their level of education varied, all were described as intelligent and often as being brighter than their husbands.

In terms of their interview behavior we could roughly divide the mothers into two groups: those who were overtly affable, narcissistic, socially upwardly mobile, and rather charming though superficial women, and those who were described as cold, withholding, Victorian, rigid, as well as suspicious, hostile, and withdrawn individuals. Despite these differences in their style of approach to the world and in their specific type of psychopathology, we were struck by several noteworthy similarities among these women. The most salient characteristic was that they appeared "unknowable" to us. Several of the psychiatrists independently and spontaneously remarked in their evaluations that they were not able to get a "feel" for what these women were like as individuals. They impressed the interviewers as peculiarly "empty" and lacking in human substance. Regardless of the content of a given communication, there was a lack of depth to the affective expression. The women appeared strangely "selfless' without obvious "gut reactions" and as if limited in their ability to recognize and respond to their own needs or to the real needs of others. In many ways they reminded one of the "as if" personality described by Helene Deutsch [27]. Despite this peculiar emptiness, however, many functioned well in their role as housewives and displayed a stoic determination to "make it" even under the most stressful conditions. Very reminiscent of the description by Lidz, Cornelison, Terry, and Fleck [28] of "masking" in the family relations of schizophrenics, these women avoided open conflict within the family by not acknowledging problems or by failing to respond to them in a reality-oriented way. They avoided arguments within the family at all costs, and it was striking how the majority of them did not voice any complaints while reciting the traumatic events that had characterized their married lives. While the details of the histories related by them would have clearly marked these women as martyrs, they usually did not recount their stories with an air of martyrdom or self-pity. On the contrary, some even seemed to gain strength by surmounting trauma and by pitting themselves against an adverse fate. For example, one mother stated that following nine toxemic and crippling pregnancies, her husband became both impotent and paranoid. At the same time, she developed a serious back pain which was found to be the result of a spinal carcinoma. The disease required repeated surgery carried out during 20 hospitalizations in a six-year period. Despite this phenomenal hardship, this woman was always able to resume her family duties and seemed in no way depressed by the experience. While the pride taken in being able to withstand so much pain, the insistence on the virtue in triumphing over adversity, and the inordinate investment in living out an idealized image of herself were telling of a great amount of strength, the narcissistic gain was also very apparent. 
Much of what these women said about themselves and their marriage was phrased in terms of cliché-ridden, idealized images of motherhood and wifehood. Their identities appeared to be fictions, mere pseudo-identities based on cliché-guided substitute representations of self (cf. Rogers [29]). Thus, it was almost impossible to get any experiential data about their own childhood, their married lives, or the early history of their children. In response to specific questions, many of these mothers eulogized their parents and their own childhood in such generalities as "My parents were tremendous" and "I had a wonderful childhood." These statements were made with great conviction, yet even after extensive questioning by an interviewer they could not provide anecdotes to meaningfully illustrate their contention. They presented themselves as the epitome of the "spirit of motherhood." Their answers to questions about themselves reflected self-righteous morality and emphasized duty-boundedness, selflessness, piety, obedience, patriotism, tolerance, and sometimes self-sacrifice. Their statements about people in general and their families in particular were also couched in such sterotypies. In their relationship to their sons it was evident that the boys were expected to see the world in these same terms, regardless of how well they agreed with internal or external reality (cf. Stierlin [30]).

From what little background information we were able to gather from other sources, it appeared that most of the women were ambivalently tied to their own mothers. They themselves described their mothers as having been more adequate and stable, as well as more psychologically present, than their fathers. Despite this, however, most clearly idealized their fathers while describing them as "beyond reach." Their fathers were apparently stern, rigid, and rejecting men, who became violent and punitive whenever their daughters or wives showed any interest in emancipation or independence. Such descriptions were not offered in criticism but instead were related with an air of admiration and an envy of the fathers' manliness. Listening to these women, one could get fleeting glimpses of a relatively puritan environment in their own childhood-an environment in which "virtue was its own reward" and no other support for leading a "good life" was either given or expected. The nature of the mothers' relationships to their own parents must have been such that basic needs and feelings were devalued, ignored, or dismissed, while there was simultaneously an implicit and constant demand for a total conformity with parental ideals of child behavior. It appears that the quality of emptiness seen in these women originated in a substitution of an ideal for a real self-representation. Their real feelings were so completely covered over that they lived out a pseudo-existence and eventually became unable to experience dissonance within themselved. That which was potentially contradictory to the ideal self-image had no existence for them and therefore did not need to be taken into account. A substitution of this sort would explain their apparent lack of communication with their own feelings and 
the insensitivity to those of other people. Despite obvious pathology, the son and husband were described as "ideal." Those portions of their behavior that did not coincide with the mother's expectations as based on her ideal images of them were largely ignored or employed to reinforce her own self-image qua ideal self. Thus the active denial actually stems from a basic and pervasive characterological inability to recognize certain aspects of reality.

In parallel to their vagueness and lack of detail about their own history these women could give neither detailed nor consistent accounts of their sons' early history. Whatever information they were able to provide was plainly superficial. All the mothers showed a strong tendency to deny their sons' illness by viewing the bizarreness and eccentricity as a virtue, describing the peculiar fantasy preoccupations, frank delusions, and other symptomatology as signs of "childish inventiveness" or rationalizing it by saying, "He's a genius and therefore different," "He is just too smart," and so on. When they could not avoid responding to someone else's complaints about their sons, they used projection and externalization of blame to avoid recognizing the sons' disturbance. The most common objects for such blame were the schoolteacher and, in some cases, the father. However, responsibility was easily displaced to more distant objects, for example, neighbors, other family members, or the hospital personnel. When these defenses failed, the unity with the son would be finally disrupted, and the mothers would then express a helpless and guilt-inducing bewilderment that went something like this: "The teacher says you don't act right. How can you be so bad when I have done so much for you?"

These women were usually unaware of the obviously reinforcing influence that their own behavior and attitudes had had on the child's pathology. Only two mothers thought that their sons' difficulties were related to their own ways of managing them. But even in these instances the mothers were far more concerned about how their sons' difficulties in school and elsewhere reflected on them as mothers than about how their mismanagement might have affected the child.

The need for maintaining the described defensive stance of not recognizing their sons' pathology was indeed intense in these women, and it played a very important role in their marital relationships. These women had strong guilt feelings because of their unconscious rejecting attitudes towards their sons. Open rejection broke through only sporadically, however, and only in a few women when the sons' individuality impinged too strongly on the mothers' needs. Such incidents arose when the sons violated an unspoken house rule to see, think, and feel things just as the mother did, regardless of the reality distortions involved. One mother, for example, literally wanted her son out of the house and actually told him he was "crazy" when he began to perceive and comment on his parents' marital discord. Another mother did not go so far as to openly reject her son but 
categorically denied every correct observation her son had made about the clearly pathological behavior of his alcoholic and paranoid father.

More typically, however, these women masked their hostility toward their sons with a debilitating overprotectiveness, but this was accompanied by an inability to control and discipline the child in a consistent fashion. The youngsters were often allowed, and at times even encouraged, to act out their infantile omnipotence, particularly in relation to persons other than the parents. Furthermore, the boys were not encouraged to find age-appropriate outlets for their needs since the mothers abetted the sons' involvement in fantasy. One mother regularly made the rounds of all the libraries in town to provide her son with the latest books and materials about astronomy at a time when he had already developed a highly structured delusional system about himself as the "king" of various planets.

Moreover, the overprotectiveness which continued the sons' dependency was not maintained in all areas as is the case with highly inhibited and anxious neurotic youngsters. Rather, it alternated with a lack of care for and attention to the child. The mothers acted in a highly possessive, intrusive, and overprotective way toward their sons in situations that involved "danger" from people (peers, the father, the school, the neighbors, the hospital, and so forth) who might take away this cherished "possession," the "genius." When the danger was real in terms of threatening physical harm to the child, these women could be totally oblivious to reality, ignoring the child completely. For example, one mother was chatting with a psychologist, unconcerned about her son who, in her full view, moved his fingers closer and closer to an electric fan. The psychologist finally became so so concerned that he intervened to keep the boy from injuring himself. Meanwhile, the mother simply stood by, watching the incident impassively. At the same time, however, these women showed a strong need to know all about their sons' inner lives and constantly invaded their privacy while claiming that only they could really understand their sons. This excessively intrusive interest in every detail of the boys' thoughts and activities was accompanied by extreme restrictions on the boys' freedom as well as by constant warnings about what were the most unlikely agressive and/or sexual attacks from other people. One mother, for example, self-righteously described how she had warned her son to be wary of homosexual advances from peers in kindergarten. Another mother had insisted on regularly accompanying her embarrassed 10-year old son to the YMCA where all the boys swam in the nude.

When evaluated, all of the boys had a highly ambivalent dependent tie to their mothers. The particular aspect of the ambivalence being acted out by each boy depended on his total situation. When a boy was afraid of attack or rejection by other people (i.e., peers, teachers, neighbors, or occasionally his father), he would typically flee the situation and then seek and receive 
protection from his mother. The mother, in turn, would generally not recognize the precipitant for her son's anxiety and either responded with a nonspecific "there, there" type of support or else blamed the trouble on the outsider. When not in flight from some real or imagined attack, the boys behaved in a highly bossy, often verbally hostile fashion with their mothers. The mothers were highly inconsistent in response to such behavior and therefore weakened the boys' understanding of reality. The mothers unpredictably alternated between severely punishing willful behavior and literally catering to the boys' whims and wishes in a slavelike manner.

\section{The Fathers}

The fathers, too, showed obvious psychopathology. The interviewers described the fathers as crude, gruff, and sadistic individuals, some of whom had manifested a brittle facade of obsessive-compulsive defenses (cf. Cameron and Cameron [31]). The majority were alcoholic, and three among these were clearly paranoid. In the remaining fathers we found a prevalence of obsessive-compulsive symptomatology, as well as variously severe psychosomatic problems ranging from insomnia to asthma. The fathers' relationships with their own parents, their wives, and their children were most often characterized by a combination of immaturity, impulsivity, and dependency. All were patently narcissistic. To pursue personal goals, some sporadically neglected their family duties by literally deserting their wives and children. Others ran their homes as tyrants, openly acting in an arbitrarily demanding and selfish way. All were given to episodic outbursts of aggression that occasionally included physical brutality toward their wives and children. Furthermore, their behavior with their family was like that of the mothers, often unpredictable and inconsistent, ranging from the described counterdependency to periods of marked dependency on their wives and/or their own mothers. One of these fathers, for example, became utterly helpless for an extended period of time after he failed with an initially successful business venture. He blamed the failure on his brother's mismanagement, sat around without making any effort to find another job, and totally gave in to his passive receptive needs.

Like their wives, these men tended to come from families where their relationships to their own parents were ridden with conflict. Discord with and overt rejection by their own fathers and an overly dependent, submissive relationship to their own mothers were the rule. In fact, several of the fathers were still under the direction of their own mothers when we met them. One father, for example, beat his wife and children because his mother said it was the proper disciplinary measure to use on them. Three others also had followed their 
mothers' advice to pursue their own aspirations which led them to actually desert their own families. In most cases the fathers' vacillation between periods of dependency on their wives and submission to their own mothers contributed immensely to the stormy course of the marital relationship. The way in which the paternal grandmothers must have encouraged the fathers' dependency on them is certainly reminiscent of the mothers' similar behavior with our patients. There is also some evidence that the sons' repetition of their fathers' marked dependency on their mothers was welcomed by these fathers, as it freed them of parental responsibility. In any event, it is striking how some aspects of the pathology appear to go back for at least two generations (cf. Ehrenwald [32]).

Most of the fathers, like the mothers, rationalized, minimized, or denied their sons' pathology, but some enjoyed and thus reinforced their sons' delinquent and aggressive acts by calling them "amusing." These "mischievous acts" included the entering of neighbors' homes to charge long-distance phone calls, the breaking of expensive home appliances, and the flooding of a basement. The often direct support and encouragement to act out is illustrated by the father who returned an air rifle to his son even though he knew of the boy's threats to shoot a neighbor girl with it. Although the parents most often presented a united front in defense of their sons while at the clinic, some disagreement was apparent regarding the sons' acting out of aggression. While the fathers condoned or even abetted it, the mothers perceived it as a threat to their elaborate and long-standing efforts to contain the child's aggression within his fantasy.

The nature of the father-son relationship was, of course, highly overdetermined. The fathers' unconscious need to have their sons act out was the most apparent of the determinants. It was also evident that stressing their sons' brichtness served to bolster their own low self-esteem. It was less obvious, however, that the fathers were threatened by their dependency on their wives unless they, too, proclaimed their sons" "genius" or in some way fostered their wives' unrealistic interpretation of the boys' difficulties. In this connection it was interesting that the few fathers who did blame their "nagging wives" for their sons' problems were at the same time in a phase of heightened dependency on their own mothers and therefore less immediately needy of their wives' support and in fact more rejecting of and irresponsible toward their own families in general.

The majority of these fathers had a conflictive attitude toward their own sexuality that found its expression in either a quasi-perverse interest in their sons' bodies, particularly in possible imperfections thereof, or in a direct preoccupation with or stimulation of their sons' sexuality. The father who complained that his son's feet were too big wrapped the boy's feet regularly until the boy was over two years of age. Another complained that his son's head was pointed, and a third was unduly preoccupied with the idea that his son 
masturbated. Several of the fathers regularly "had fun" with their sons, tickling them to the point where the boys became intensely excited and anxious. All of the fathers were reported to be either exhibitionistic in their habit of parading around naked in the home or extraordinarily shy and bashful with regard to anybody in the family being seen naked. In the light of these observations we should note that we did find evidence in the psychological tests of the boys that suggested problems with body image and sexual identity. However, these difficulties were of the kind commonly found in disturbed youngsters and could not be construed as specifically homosexual in content. We would have to conclude, in regard to that aspect of psychoanalytic theory that links guilt about specific homosexual impulses to the paranoid development, that this is not a necessary condition for the evolution of paranoid thinking. What seems more important is the child's continued subjugation to the dominant and conflicting unrealistic ministrations of both parents.

Outside of the described part-object interests in their sons' bodies and more sexual-aggressive activities, the fathers were much less involved with their sons than were the mothers. In contrast to the mothers, the fathers were also less insistent on and pervasive in their denial of their sons' problems. They appeared more real, less barricaded and defended, as well as more aware of their own and their sons' difficulties. They were not without serious problems but were more open in admitting them. A few openly described fears of going "crazy," and others felt that they should not have had children as their family was "tainted" with mental illness. Despite these admissions of concern, however, they did not seem to have the lasting interest in doing anything to help themselves or their youngsters and would, by default, simply go along with whatever decisions their wives made about their sons.

\section{Summary and Discussion}

From the foregoing description of these families it becomes apparent that these 13 paranoid boys grew up with parents who related to each other and their sons primarily on a part-object basis. Each parent used the son to fulfill one or more unconscious needs of his own, and thus the child received only sporadic and incidental attention when his behavior could be used by the parents to suit their own needs. The typical father seemed mainly involved with his son's impulse life, tending to encourage and condone the boy's aggressiveness, unrealistically finding fault with him for some physical inferiority, and showing a thinly veiled libidinal interest in the boy's body. The typical mother "took possession" of the youngster's mental life and eulogized him as brilliant. She greatly encouraged the child's original gift of storytelling, praised him for his 
imagination and creativity, provided him with ever-new materials for his "scientific interests," and simultaneously disregarded the implicit pathology by rationalizing his retreat as necessary or as nothing to be concerned about. Both parents, but particularly the mother, fostered the formation of the delusions.

The resulting paranoid adjustment including the delusions may be understood as an effort on the boy's part to develop some sense of autonomy and control while simultaneously coordinating as many sets of need-gratification pairs as is possible when the needs in question originate in three people. The idea of the child's adapting to his parents' expectations of him in a way that gratifies many of his own needs as well is of course not new and is, in fact, part and parcel of all child development theory. What differentiates the development of our subjects from that of the normal child is their exposure to the inability of these parents to perceive (mother) or to respond (father) to the child's needs if different from their own. We are not saying that these parents never gratified their sons' needs. Rather, we suggest that the patients' needs were met only by coincidence when they coincided with those of their mothers and/or fathers. By analogy, a child who is fed when his mother is hungry rather than when he is hungry will not starve. He will, however, come to experience the world as an unpredictable, untrustworthy, and frustrating place in which he does not count. As he adapts the timing of his hunger to that of his mother, he may develop some sense of security, and the world may become somewhat more reliable and predictable for him. In the unpredictable morass of reward and punishment in which these youngsters grew up, there was peace in conforming to parental demands. As was described in detail, the boys tried their best to live up to their assigned role of "genius" which not only gratified many unconscious needs of their mothers (and sometimes their fathers) but also brought them the attention and protection from mother that was a "better than nothing" substitute for love. The grandiose and omnipotent elements in their early fantasy life and later delusions were used by the parents as evidence for their sons" "greatness" and were needed by the boys as a defense against anxiety over strong feelings of insignificance. Furthermore, in their fantasies and delusions the boys became important individuals, and events became more predictable and controllable in a preordered world.

As long as the boys spent most of their time at home, very much tied to and dependent on their mothers, they appeared more or less normal-at least in their mother's eyes. With her help they could avoid peers and bask in the reflected approval accumulating from their astonishing facility to converse with adults. They spent much of their time on a science project and with books that their mothers had brought them. They contained most of their aggressive and libidinal strivings in an increasingly elaborate fantasy world. The normal expression of needs for independence and privacy were ignored or discouraged. The necessary ingredients that lead to a feeling of trust and later to autonomy were not 
provided. On the contrary, by example or direct teaching the mothers in particular instilled in their youngsters a distrust of others. They taught the child to blame other people for trouble, and they hampered the child's physical exploration of the extrafamilial world (see Lidz et al. [28]). Even within the family the boys were expected to see, hear, and say things in a way that fit with mother's stereotyped and/or idealized way of viewing herself in the family. At the same time, unrealistic demands arising from unmodified feelings of infantile omnipotence were experienced by these parents as welcome evidence of the child's "genius" and were encouraged.

By the time the child experienced the demands and expectations of the extra-familial world (i.e., when he went to school), his techniques of relating to people were already so deformed that the confusion and rejection he experienced in the real world only helped to reinforce the mistrust his mother had taught him. The anxiety and fear that was engendered by the boy's helplessness with peers also contributed to his withdrawing more into the already well-established fantasy world, and the ensuing failure to experience refutation of his fantasies gradually led him into a delusional belief. His learned mistrust of other people began to make sense to him for the first time as it was fueled by peer rejection as well as by adult irritation and exasperation. Furthermore, the total peer rejection that these boys experienced reinforced a vague but growing sense of being different from other people.

Our findings tend to support the statement of Cameron [33] who indicated that the abrupt onset of paranoid delusions is only illusory. Among our child patients the fantasies became more and more elaborated in content and appeared increasingly "real" as the child simultaneously increased his withdrawal from the real world. We find childhood delusions to develop within the context of a slow process of acquisition of distorted perceptions. The withdrawal from reality was ordained by the styles of the parents (particularly the mothers) and catalyzed by the hurtful confrontation with peers and others outside the family who did not share the child's learned viewpoints and caused the child to become even more cautious in putting forth his ideas. Those parts of the real world that did not contradict the fantasies and/or delusions were retained.

The implications of this study can be summarized as indicating that the child who is to become a paranoid schizophrenic is one who will have had a pattern of disturbed development from infancy onward. There was no evidence of biologic abnormalities occurring with sufficient frequency to be accorded the status of an etiological factor. Rather, the origins of such disorders are to be sought in the differing personality styles of the parents. While the mother has primary responsibility for raising the child, the father also contributes to the environmental influences indirectly by supporting the mother in her unrealistic, cliché-ridden distortions of her self-image and her assessment and understanding 
of objective reality and more directly by fostering an entirely different kind of reality in her relationship with the child. The mother emphasizes the ideational side, the father the affective and impulsive components. Neither represents reality, for both fail to help the child integrate the two aspects of his experience. This sets the stage for an early split in the personality. In addition, the parents both tend to deny the child's realistic experiences and perceptions, substituting instead their own distorted views and interpretations of his experience that grow from their experience. They thus foster the child's failure to separate and individuate, and promulgate the continuation of his narcissism. They prohibit corrective influences stemming from the environment outside the home, both by making prejudicial statements about the dangers in the world, thus leading to the child's being too frightened to make any contacts, and by always taking his side in any difficulties he has and blaming the "bad" others for the incident. The reinforcement offered the child to maintain if not increasingly strengthen the tie to the family is difficult for the child to reject since there is little hope of finding similar satisfaction in a world he is unprepared to deal with.

Dr. Arthur is Associate Professor, Departments of Psychiatry and Psychology, Children's Psychiatric Hospital, the University of Michigan Medical Center, Ann Arbor, Michigan 48104.

Dr. Schumann is in private practice at 298 Ridgeway Drive, Eugene, Oregon, 97405.

\section{References}

1. Freeman T, Cameron JL, McGhie A: Studies on Psychoses. New York, International Universities Press, 1966.

2. Biren JE: Psychological examinations of children who later became psychotic. $J$ Abn Soc Psychol 39:84-95, 1944.

3. Nameche G, Waring M, Ricks D: Early indications of outcome in schizophrenia. J Nerv Ment Dis 139:232-40, 1964.

4. Robins LN: Deviant Children Grown Up: A Sociological and Psychiatric Study of Sociopathic Personality. Baltimore, Williams \& Wilkins, 1966.

5. Klein M: Notes on some schizoid mechanisms. Int J Psa 27:99-110, 1946.

6. Heimann P: Certain functions of introjection and projection in early infancy. in $J$ Riviere (Ed), Developments in Psychoanalysis. London, Hogarth Press, 1952.

7. Josephs B: Persecutory anxiety in a four-year-old. Int J Psa 47:184-88, 1966.

8. Kanner L: Child Psychiatry. Springfield, Ill, Thomas, 1957.

9. Bender L, Lipkowitz HH: Hallucinations in children. Amer J Orthopsychiat 10:471-90, 1940.

10. Despert JL: Delusional and hallucinatory experiences in children. Amer $J$ Psychiat 104:528-37, 1948.

11. Pearson GH: Emotional Disorders of Children. New York, Norton, 1949.

12. Sullivan HS: Clinical Studies in Psychiatry. New York, Norton, 1956. 
13. Laroche J: Réflexions à propos du délire chez l'enfant. Evolut Psychiat 25:219-52, 1960.

14. Harrison SI, Hess JH, Zrull JP: Paranoid reactions in children. J Amer Acad Child Psychiat 2:677-92, 1963.

15. Kessler JW: Psychopathology of Childhood. Englewood Cliffs, NJ, Prentice-Hall, 1966.

16. Lidz T, Fleck S, Cornelison AR: Schizophrenia and the Family. New York, International Universities Press, 1965.

17. Bateson G: The biosocial integration of behavior in the schizophrenic family. In W Ackerman, F Beatman, and S Sherman (Eds), Exploring the Base for Family Therapy. New York, Family Service Association of America, 1961.

18. Jackson D, Weakland J: Schizophrenic symptoms and family interaction. Arch Gen Psychiat 1:618-21, 1959.

19. Wynne LC, Ryckoff IM, Day S, et al: Pseudo-mutuality in the family relationships of schizophrenics. Psychiat 21:205-20, 1958.

20. Nameche G, Ricks DF: Life patterns in children who became adult schizophrenics. Paper read at the American Orthopsychiatric Association meeting in San Francisco, April 16, 1966.

21. Kovar L: A reconsideration of paranoia. Psychiat 29:289-305, 1966.

22. Schwartz DA: a re-view of the "paranoid" concept. Arch Gen Psychiat 8:349-61, 1963.

23. Schmiderberg M: A contribution to the psychology of persecutory ideas and delusions. Int J Psa 12:331-67, 1931.

24. Will OA, Jr: Paranoid development and the concept of self: Psychotherapeutic intervention. Psychiat 24:74-86, 1961.

25. Freud S: Constructions in psychoanalysis. Collected Papers, vol 5. London, Hogarth Press, 1950.

26. Eissler RS: About the historical truth in a case of delusion. Psa Rev 33:442-59, 1946.

27. Deutsch H: Some forms of emotional disturbance and their relationship to schizophrenia. Psa Q 11:301-21, 1942.

28. Lidz T, Cornelison AR, Terry D, et al: Intrafamilial environment of the schizophrenic patient. VI. The transmission of irrationality. Arch Neurol Psychiat 79:305-16, 1958.

29. Rogers AH: The self-concept in paranoid schizophrenia. J Clin Psychol 14:365-66, 1958.

30. Stierlin H: The adaptation to the stronger person's reality: Some aspects of the symbiotic relationship of the schizophrenic. Psychiat 22:143-52, 1959.

31. Cameron N, Cameron MA: Behavior Pathology. Boston, Houghton, Mifflin Co, 1951.

32. Ehrenwald J: Neurosis in the Family and Patterns of Psychosocial Defense: A Study of Psychiatric Epidemiology. New York, Hoeber, 1963.

33. Cameron N: The development of paranoid thinking. Psychol Rev 50:219-33, 1943. 